\title{
Vigilance of mustached tamarins in single-species and mixed-species groups - the influence of group composition
}

\author{
Mojca Stojan-Dolar • Eckhard W. Heymann
}

Received: 30 January 2009 / Revised: 28 July 2009 / Accepted: 30 August 2009 / Published online: 25 September 2009

(C) The Author(s) 2009. This article is published with open access at Springerlink.com

\begin{abstract}
Species that participate in mixed-species groups (MSG) may have complementary roles in antipredator strategies. We studied vigilance in mustached tamarins (Saguinus mystax), small arboreal primates that form stable mixed-species groups with saddleback tamarins (Saguinus fuscicollis), in order to examine how the direction of vigilance changes with different species group compositions and whether the division of labor between the two species can be confirmed. We did so by comparing quantitative and qualitative differences in vigilance behavior between same individuals in and out of association (case A); MSG and single-species groups of the same total group size from two different populations (case B); and MSG of the same group size but with a different ratio of conspecifics to heterospecifics (case C). We predicted that individuals would increase downward scanning when heterospecifics are absent or their percentage is low, but total vigilance would increase only in case A due to the group size effect. However, mustached tamarins increased total vigilance due to horizontal scanning in cases A and $\mathrm{C}$, and the predictions were confirmed only in small-sized groups in case B. Thus, we found indications that associating tamarin species in MSG might complement
\end{abstract}

Communicated by D. Watts

M. Stojan-Dolar $(\bowtie) \cdot$ E. W. Heymann

Department of Behavioural Ecology and Sociobiology,

German Primate Centre (DPZ),

Kellnerweg 4,

37077 Göttingen, Germany

e-mail: mojca.stojan@arnes.si

M. Stojan-Dolar

Department of Sociobiology/Anthropology,

Georg-August-University of Göttingen,

Kellnerweg 6,

37077 Göttingen, Germany each other in the direction of vigilance, but the division of labor alone does not satisfactorily explain all the findings. There appear to be other mechanisms at work that define how direction of vigilance changes with group size and species composition. Complementarity of species probably occurs due to species vertical stratification rather than differences in the direction of vigilance.

Keywords Vigilance $\cdot$ Mixed-species groups $\cdot$ Saguinus mystax . Antipredator behavior $\cdot$ Species complementarity . Primates

\section{Introduction}

Mixed-species groups (MSG) can be observed in a number of vertebrate taxa including fish (Ehrlich and Ehrlich 1973; Semeniuk and Dill 2006), birds (Morse 1977; Thompson and Barnard 1983; Metcalfe 1984; Munn 1986) and mammals (Struhsaker 1981; Cords 1990; Fitzgibbon 1990; Shelden et al. 1995; Herzing and Johnson 1997; Heymann and Buchanan-Smith 2000). Benefits of forming such associations are considered in terms of predator detection and avoidance, increased foraging efficiency, and reproductive advantages (reviewed in Stensland et al. 2003). However, antipredator benefits are most often considered as the ultimate cause leading to the evolution of MSG (Thompson and Barnard 1983; Munn 1986; Fitzgibbon 1990; Noë and Bshary 1997; Semeniuk and Dill 2006), and in primates strong predation pressure may even be one of the preconditions for MSG formation (Struhsaker 1981; Gautier-Hion et al. 1983; Terborgh 1990). Larger single-species groups (SSG) are supposed to be safer due to both the detection (Pulliam 1973) and dilution effects (Hamilton 1971). Individuals in MSG have the same antipredator advantages 
as animals forming SSG, while avoiding increased intraspecific competition for food and mates, which poses a limitation on how large SSG can be (Terborgh 1990; Caine 1993; Hardie and Buchanan-Smith 1997).

Besides contributing to group size, heterospecifics might also have a complementary role in antipredator behavior. Associated species may occupy different microhabitats or show physiological differences in perception and could therefore differ in the type of stimuli they are more likely to detect. In primates, species mainly residing in higher forest strata are often more likely to detect and to warn against aerial predators, while species mainly residing in lower strata are more likely to detect and to warn against terrestrial predators (Gautier-Hion et al. 1983; Peres 1993). The presence of one species can change the direction of vigilance and habitat use of another (Bshary and Noë 1997; Porter 2001; McGraw and Bshary 2002; Wolters and Zuberbühler 2003).

Mustached tamarins (Saguinus mystax) are cooperatively breeding arboreal New World primates that provide an interesting model for a study of vigilance. They have a highly cooperative social system with low levels of agonistic within-group interactions and lack an apparent dominance hierarchy (Heymann 1990b, 1996). Due to their small body size, they are a subject to strong predation pressure, mostly by large raptors but also by snakes and terrestrial predators such as ocelot and tayra (Galef et al. 1976; Terborgh 1983; Heymann 1990a; Peres 1993; Oversluijs Vasquez and Heymann 2001; Shahuano Tello et al. 2002). They form stable mixed-species groups with saddle-back tamarins (Saguinus fuscicollis), and shared vigilance is proposed to be one of the major reasons for the formation of such groups (Heymann and Buchanan-Smith 2000). Peres (1993) suggested that the two species, which show vertical stratification in the forest, might additionally enhance predator detection by functional division of labor in antipredator vigilance. $\mathrm{He}$ found that mustached tamarins that occupy higher levels of the forest were usually the first to emit alarm calls to aerial predators, and lower-living saddleback tamarins were more likely to warn against terrestrial predators. Similarly, in captive MSG of tamarins the higher-ranging species was quicker to discover objects at higher levels, and the lowerranging species was quicker to discover objects on the floor (Hardie and Buchanan-Smith 2000). The aim of the present study is to examine whether this division of roles is reflected also in the direction of vigilance. The results in the literature are inconsistent: captive red-bellied tamarins (Saguinus labiatus) and wild mustached tamarins were found to spend more time looking upwards or sideways than lower-living saddleback tamarins, and saddlebacks spent more time looking downwards than the higher-living species (Peres 1993; Buchanan-Smith and Hardie 1997). While this supports the idea of the division of labor, Smith et al. (2004) and Kirchhof (2003) came to opposing results in wild mustached-saddleback MSG. When focusing on the direction of vigilance in mustached tamarins only, results from different studies are confusing already due to differences in how direction of vigilance was recorded: Peres (1993) reports more looks sideways or up than downwards, Kirchhof (2003) slightly more looks upwards than downwards, and Smith et al. (2004) more side-sweeps than look-ups.

In a previous study, we already demonstrated the group size effect and the importance of proximity of conspecifics as well as heterospecifics on vigilance of mustached tamarins living in associations with saddle-back tamarins (Stojan-Dolar and Heymann 2009), which indicates that the presence of heterospecifics contributes to safety in tamarin MSG. Here, we examined how the direction of vigilance changes with different species group compositions and whether the division of labor between the two species can be confirmed. We did so by comparing quantitative and qualitative differences in vigilance behavior between MSG and SSG. In the wild, this kind of comparison is very difficult because tamarin MSG are so stable that they can rarely be observed out of association (Buchanan-Smith and Hardie 1997). We solved this problem by including an isolated population of mustached tamarins that lives on an island where no other primates are present and forms SSG of comparable size to that of MSG in the wild. The following comparisons were made (Fig. 1): MSG and SSG within the same wild population (same individuals in and out of association) (comparison A); MSG and SSG of the same total group size from two different populations (comparison B), and MSG of the same group size but with a different ratio of conspecifics to heterospecifics (comparison C). If larger groups are safer and the lower-living saddleback tamarins are more likely to detect terrestrial threats, the following predictions can be made: (1) Individuals in groups that usually associate with saddleback tamarins will increase their total vigilance when out of association and especially increase the percentage of time spent scanning downwards. (2) Individuals in SSG will show similar levels of vigilance as individuals in MSG of the same size but would spend more time scanning downwards. As for the third comparison, it is possible that a mere difference in the percentage of heterospecifics does not cause a response in individual vigilance behavior, but if it does individuals in the group with less heterospecifics would be expected to (3) spend more time looking downwards, whereas total vigilance levels in groups of the same size should not change.

\section{Methods}

Study sites and subjects

Wild mustached tamarins were observed at two study sites in the northeastern lowlands of Peruvian Amazonia. The 


\begin{tabular}{|c|c|c|c|c|}
\hline Comparisons & \multicolumn{2}{|c|}{ Total vigilance } & \multicolumn{2}{|l|}{ Direction } \\
\hline & Prediction & Confirmed? & Prediction & Confirmed? \\
\hline $\begin{array}{lll} & \mathrm{m} & \mathrm{m} \\
\mathrm{A} & \mathrm{s} & \end{array}$ & Increase & Yes & $\begin{array}{l}\text { More downward } \\
\text { vigilance }\end{array}$ & $\begin{array}{l}\text { No, more } \\
\text { horizontal } \\
\text { vigilance }\end{array}$ \\
\hline B $m m$ & $\begin{array}{l}\text { Approximately } \\
\text { the same }\end{array}$ & Yes & $\begin{array}{l}\text { More downward } \\
\text { vigilance }\end{array}$ & $\begin{array}{l}\text { Yes, but only the } \\
\text { smaller group }\end{array}$ \\
\hline c $\quad \begin{array}{lll}m & m \\
& & \end{array}$ & $\begin{array}{l}\text { Approximately } \\
\text { the same }\end{array}$ & $\begin{array}{l}\text { No, total } \\
\text { vigilance } \\
\text { increased }\end{array}$ & $\begin{array}{l}\text { More downward } \\
\text { vigilance }\end{array}$ & $\begin{array}{l}\text { No, more } \\
\text { horizontal } \\
\text { vigilance }\end{array}$ \\
\hline
\end{tabular}

Fig. 1 Schematic illustration of group sizes and compositions used in comparisons $\mathrm{A}, \mathrm{B}$, and $\mathrm{C}$ and related predictions. Each bar represents a tamarin group. Black represents the mustached tamarins complement of the group $(m)$, white represents the saddleback

first site, Estación Biológica Quebrada Blanco (EBQB), is located about $70 \mathrm{~km}$ southeast of Iquitos $\left(4^{\circ} 21^{\prime} \mathrm{S}, 73^{\circ} 09^{\prime} \mathrm{W}\right)$ and is covered by primary tierra firme forest (see Heymann 1995 for details). Mixed-species groups of tamarins have been continuously followed for at least 6 years before the onset of this study. Three groups of mustached tamarins were observed for 136 days between February 2006 and March 2007 , covering both rainy and dry season. During the rainy season, each group was observed for 5-6 days every month, and during the dry season each group was observed for $5-6$ days every second month. The mean group size ( \pm SE) was $6.6 \pm 0.2$ (range, 5-9), including $2.9 \pm 0.1$ adult males (range, 2-5) and $1.6 \pm 0.1$ adult females (range, 1-2). They formed stable mixed-species groups with $5.1 \pm 0.3$ saddleback tamarins (range, 2-8).

The second location, Padre Isla (PI), is an approximately $8 \mathrm{~km}^{2}$ island on the Amazon River near Iquitos $\left(3^{\circ} 44^{\prime} \mathrm{S}\right.$, $73^{\circ} 14^{\prime}$ W) (described in Heymann 1990b). No primates originally lived on the island, but in 1977, 1978, and 1980, 87 wild-trapped S. mystax were released there by the Peruvian Primatological Project (Ique 2000). The island is covered by seasonally flooded (January-May) secondary forest and fruit and yuca plantations. Observations were only possible during the dry season. There are human settlements on the island, so this population is used to human presence, and groups have occasionally been followed by researchers (e.g., Heymann 1990b; Garber et al. 1993; Garber and Pruetz 1995; Tornow et al. 2006). However, in order to minimize the potential problems resulting from comparing populations with different degrees of habituation, we followed the monkeys for 2 months before starting the observations. After this additional habituation period, the monkeys did not pay more attention to observers than those at EBQB. Two groups of mustached tamarins were observed for 63 days tamarins complement $(s)$. Predictions regarding the changes in total vigilance levels and in direction of vigilance refer to the group depicted on the right compared to the group depicted on the left in each case

between August 2006 and January 2007. Each group was observed for approximately 10 days every second month. The mean group size $( \pm \mathrm{SE})$ was $10.75 \pm 0.68$ (range, $8-14$ ), including $2.42 \pm 0.47$ adult males (range, $1-5$ ) and $2.75 \pm$ 0.13 adult females (range, $2-3$ ). Since no other primates are present, mustached tamarins on PI live in single-species groups (SSG). Animals at both sites were individually identified by differences in pelage patterns, body size, and shape and pigmentation of reproductive organs (Löttker et al. 2004). None of the observed females was in estrus.

\section{Observation methods}

Vigilance was defined as observable head movements in stationary animals where scanning is directed beyond arm's reach (Treves 1998). Looking at their own body, body of a grooming partner, objects close to their own body, or objects held in hands was not considered as vigilance. Looking beyond arm's reach was excluded in two cases, since it is reasonable to assume that in these situations animals cannot effectively perceive the environment: (a) staring without head movements in an unusual head position (when head is turned upside-down and eyes are lower than the mouth) while being groomed, and (b) when an animal is scratching its head in such a way that the head shakes.

Continuous focal sampling (Martin and Bateson 1990) was used to record vigilance status (vigilant, not vigilant), the direction of scanning (up, down, horizontal), and individual activity. Scanning upwards was defined as looking towards the sky at an angel of at least $45^{\circ}$, scanning downwards was defined as looking towards the ground at an angel of at least $45^{\circ}$, and scanning in between was considered as horizontal. With every observation, data on the height of the focal individual was also collected, and a height class was ascribed to every observation $(0$, ground; 
1, 0-3 m; 2, 3-6 m; 3, 6-9 m; 4, 9-12 m; 5, 12+ m). We chose the focal animal based on which individuals were visible in order to maximize the amount of data collected. When a choice was possible, we chose the individual with least observations, unless it had been the focal animal during the previous $30 \mathrm{~min}$. The activities were defined as follows: resting - sitting or laying without being engaged in any activity that requires visual attention; feeding - ingesting food or searching for prey using one or both hands to investigate leaves, bark, holes etc.; allogrooming — going through the fur of another individual with the hands; autogrooming - going through own fur with the hands. In order to evaluate the suitability and reliability of the definition of vigilance, a reliability test was performed prior to data collection.

Observation conditions allowed for $30-120 \mathrm{~s}$ focal observations. Data were entered directly into a hand-held computer using The Observer Mobile ${ }^{\circledR}$ software. The two species were considered as a MSG when at least one individual from one species was less than $20 \mathrm{~m}$ apart from one individual from the other species (Struhsaker 1981). In order to ensure independence of observations, the same individual was never resampled within a $30-\mathrm{min}$ time period.

\section{Data analysis}

For every individual, the proportion of time spent vigilant was taken as a measure of vigilance. Only individuals that had at least ten observations under specified conditions were considered in the analyses. Percentages of time spent vigilant were averaged for each individual, using only observations from groups of the specified composition. These individual mean values were used as data points in further analyses. In all cases, we used nonparametric statistical tests. The following comparisons were made:

A. Comparison of vigilance behavior of individuals at EBQB in and out of association. Since tamarins in the wild are very rarely found in SSG, we only had enough data to compare vigilance in nine individuals from different groups.

B. Comparison between MSG at EBQB and SSG at PI of the same total group size. The size of all the study groups was varying in time. There was a sufficient amount of data to include two pairs of MSG and SSG. The pair of smaller groups had a total group size of eight, and the pair of larger groups had a total group size of 13. For this analysis, it was possible to divide comparisons by activity: vigilance in larger groups was compared during resting and during feeding, whereas for smaller groups the data only allowed a comparison during resting.
Predation pressure at different sites could be different, which would influence vigilance and render the comparison difficult. Since it is not possible to measure the predation pressure directly, we recorded alarm calls emitted by tamarins as a measure of perceived predation risk (Hill and Dunbar 1998). The rate of alarm calls was almost the same for both sites, so we were able to continue the analysis without controlling for predation pressure.

C. Comparison between two MSG of the same size (14 individuals) but different species composition (43\% and $64 \%$ of mustached tamarins). The amount of data under these specific conditions did not allow for splitting by activity.

To compare heights of different groups, mean of the height class values was calculated for every individual under the specified conditions.

\section{Results}

At EBQB (comparison A), individuals increased their overall vigilance in the absence of heterospecifics (Wilcoxon exact: $T=1, N=9, p=0.020$; Fig. 2 ) due to an increase in horizontal scanning ( $T=1, N=9, p=0.008)$. There was no difference in looking upwards $(T=4, N=9, p=1.000)$ or looking downwards $(T=4, N=9, p=0.652)$.

When comparing groups of the same size at different sites (comparison B), we first compared the rate of alarm calls, which did not differ between the two sites $(0.33 \pm 0.23$ per $10 \mathrm{~h}$ of observation per individual for EBQB (mean $\pm \mathrm{SD}$ )

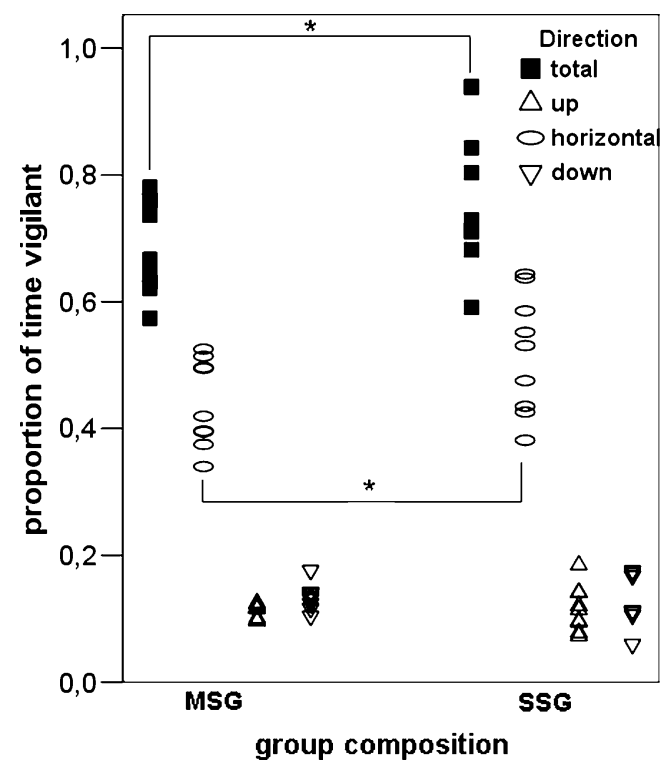

Fig. 2 Proportion of time spent vigilant for individuals at EBQB in the presence and absence of heterospecifics. Data points represent individual mean values. ${ }^{*} p=0.05$ level of significance 
and $0.33 \pm 0.11$ for PI; Mann-Whitney $U: \mathrm{n} 1=27 ; \mathrm{n} 2=6$; $Z=-0.420 ; p=0.674)$. The group compositions of our study groups enabled us to compare two pairs of groups: smaller groups with a total of eight individuals and larger groups with at total of 13 individuals. However, in both cases, data at EBQB were collected during the rainy season, while observations on PI were only possible during the dry season. Therefore, we first checked whether season affected vigilance at $\mathrm{EBQB}$ to make sure that observations collected at different times of the year are comparable. We found that vigilance during feeding was higher in the rainy season (total vigilance: $T=2, N=14, p=0.019$; up: $T=5, N=14, p=$
0.140; horizontal: $T=4, N=14, p=0.084$; down: $T=6, N=$ $14, p=0.331$; Wilcoxon exact), but vigilance during resting was not affected by season (total vigilance: $T=7, N=17, p=$ 0.906; up: $T=8, N=17, p=0.795$; horizontal: $T=7, N=17$, $p=0.356$; down: $T=6, N=17, p=0.309$; Wilcoxon exact). Possible reasons for this difference are beyond the scope of this study, but in order to avoid confounding effects we conducted comparison B only with data on vigilance during resting. The only significant difference was found in smaller groups (eight individuals) where individuals in SSG spent more time looking downwards than in MSG (Fig. 3, Table 1). Larger SSG at PI and MSG at EBQB (13
Fig. 3 Differences in the proportion of a time spent looking upwards; $\mathbf{b}$ time spent looking downwards; $\mathbf{c}$ time spent looking horizontally, and $\mathbf{d}$ total time spent vigilant between MSG at EBQB and SSG at PI controlled for the effect of the group size. Data points represent individual mean values. Open circles individuals in groups of total size 8 during resting; black circles individuals in groups of total size 13 during resting. ${ }^{* *} p=0.01$ level of significance
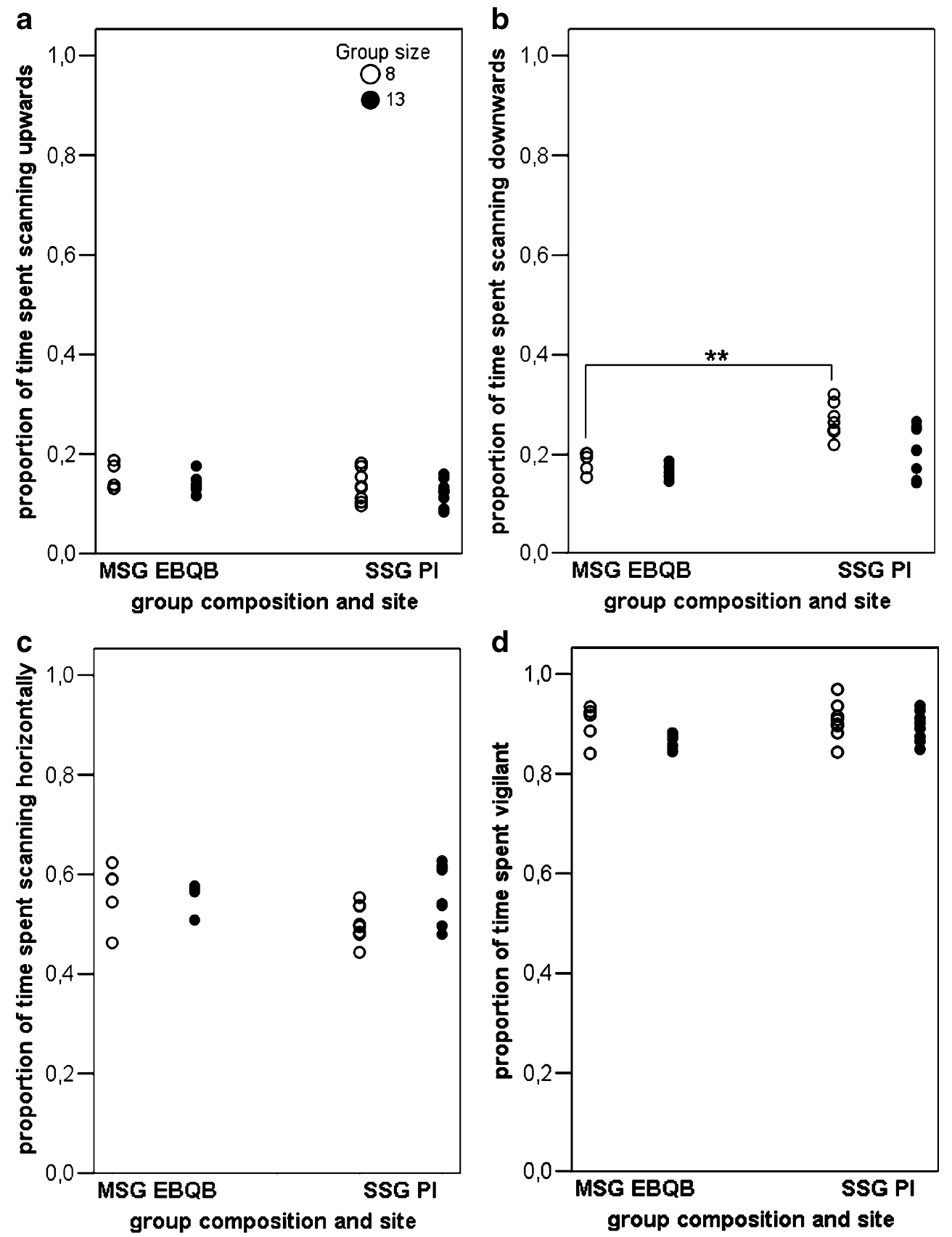
Table 1 Results of MannWhitney $U$ exact test for differences between MSG at EBQB and SSG at PI

Differences between $N_{\text {(PI) }}$ and total group size emerge because not all the individuals fulfilled the conditions to be included in the analysis (see "Methods")

** $p=0.01$ level of significance

\begin{tabular}{lcccrrl}
\hline Direction of vigilance & Group size & $N_{\text {(EBQB) }}$ & $N_{(\mathrm{PI})}$ & $U$ & \multicolumn{1}{l}{$Z$} & $p$ \\
\hline Up & 8 & 5 & 8 & 14.0 & -0.878 & 0.435 \\
\multirow{2}{*}{ Down } & 13 & 5 & 8 & 12.0 & -1.171 & 0.284 \\
& 8 & 5 & 8 & 0.0 & -2.928 & $0.002 * *$ \\
Horizontal & 13 & 5 & 8 & 11.0 & -1.317 & 0.222 \\
\multirow{2}{*}{ Total } & 8 & 5 & 8 & 8.0 & -1.757 & 0.093 \\
& 13 & 5 & 8 & 18.0 & -0.293 & 0.833 \\
& 8 & 5 & 8 & 20.0 & 0.000 & 0.999 \\
& 13 & 5 & 8 & 9.0 & -1.610 & 0.127 \\
\hline
\end{tabular}

individuals) did not differ in any component of their vigilance behavior.

In all cases, the monkeys spent two to five times more time looking horizontally than upwards or downwards (Table 2). They also tended to look more downwards than upwards during resting; this difference was significant for the larger MSG group at EBQB and for both groups at PI (Table 2).

In MSG of the same size but different species composition (comparison $\mathrm{C}$ ), individuals in the group with a higher percentage of conspecifics were more vigilant (Mann-Whitney $U: \mathrm{n} 1=5 ; \mathrm{n} 2=6 ; Z=-2.373 ; p=0.046$ ) due to differences in horizontal scanning $(Z=-2.556$; $p=$ 0.032 , Fig. 4). There were no differences in looking upwards $(Z=-0.365 ; p=1.000)$ or downwards $(Z=-0.183$; $p=0.886)$.

Individuals in SSG that were temporarily out of association (comparison A) were found higher in the forest than when they were in MSG (Wilcoxon: $T=0, N=5, p=$ 0.008). The same was true for individuals in SSG at PI compared to MSG at EBQB (comparison B) for both larger (Mann-Whitney $U: \mathrm{n} 1=5 ; \mathrm{n} 2=8 ; Z=-2.635 ; p=0.008$ ) and smaller $(\mathrm{n} 1=5 ; \mathrm{n} 2=8 ; Z=-2.781 ; p=0.005)$ pair of groups. Individuals in MSG with different percentages of conspe- cifics (comparison C) did not differ in heights (MannWhitney $U: \mathrm{n} 1=5 ; \mathrm{n} 2=6 ; Z=-1.551 ; p=0.121$ ).

\section{Discussion}

We found weak support for complementarity of the direction of vigilance between the two associating tamarin species. Only the comparison between SSG and MSG of the same size supported our prediction (comparison B, prediction 2), and that was true only for individuals in smaller groups during resting where individuals in the population that never associated with other species looked downwards more than individuals in MSG (Table 2, Fig. 3). In larger groups, there were no differences between MSG and SSG of the same size, which could imply that heterospecifics play a more important role in smaller groups, but data on more groups would be needed for firmer conclusions.

The idea of the division of labor was further supported by the analysis of directions of vigilance within groups (Table 2). Mustached tamarins in all groups tended to look downwards more than upwards, but while the difference at EBQB was of only a few percent and

Table 2 Mean, median, minimum, and maximum percentage of time individuals in groups of different group composition spent looking in the specified direction

\begin{tabular}{|c|c|c|c|c|c|c|c|c|c|c|c|c|c|c|c|}
\hline & \multicolumn{3}{|c|}{ Horizontal } & \multicolumn{3}{|l|}{ Up } & \multicolumn{4}{|c|}{ Down } & \multicolumn{5}{|c|}{ Wilcoxon } \\
\hline & Mean & Median & Min & Max & Mean & Median & Min & Max & Mean & Median & Min & Max & $N$ & $T$ & $p$ \\
\hline SSG EBQB & 51.9 & 53.1 & 38.2 & 64.4 & 11.6 & 11.4 & 7.3 & 18.5 & 13.7 & 11.3 & 6.0 & 22.3 & 9 & 15 & 0.374 \\
\hline MSG EBQB & 43.9 & 41.9 & 34.0 & 52.5 & 11.2 & 11.6 & 9.6 & 12.5 & 13.4 & 13.5 & 10.4 & 17.6 & 9 & 1 & $0.011 *$ \\
\hline $8^{\mathrm{a}}$ rest $\mathrm{EBQB}$ & 56.2 & 59.0 & 46.3 & 62.3 & 15.3 & 13.8 & 13.1 & 18.7 & 18.5 & 19.5 & 15.4 & 20.3 & 5 & 2 & 0.138 \\
\hline 13 rest $\mathrm{EBQB}$ & 55.8 & 57.1 & 50.8 & 57.7 & 14.2 & 13.8 & 11.6 & 17.6 & 16.6 & 16.4 & 14.6 & 18.7 & 5 & 0 & $0.043^{*}$ \\
\hline 8 rest PI & 50.3 & 49.7 & 44.4 & 55.3 & 13.6 & 13.4 & 9.6 & 18.2 & 26.6 & 25.7 & 21.0 & 32.0 & 8 & 0 & $0.012 *$ \\
\hline 13 rest PI & 56.5 & 57.5 & 47.0 & 62.7 & 12.2 & 12.5 & 8.3 & 16.0 & 20.7 & 20.9 & 14.3 & 26.7 & 8 & 1 & $0.017 *$ \\
\hline
\end{tabular}

Wilcoxon exact test was used to test for the difference between upward and downward scanning

${ }^{\mathrm{a}}$ The numbers in this column indicate the group size

${ }^{*} p=0.05$ level of significance 


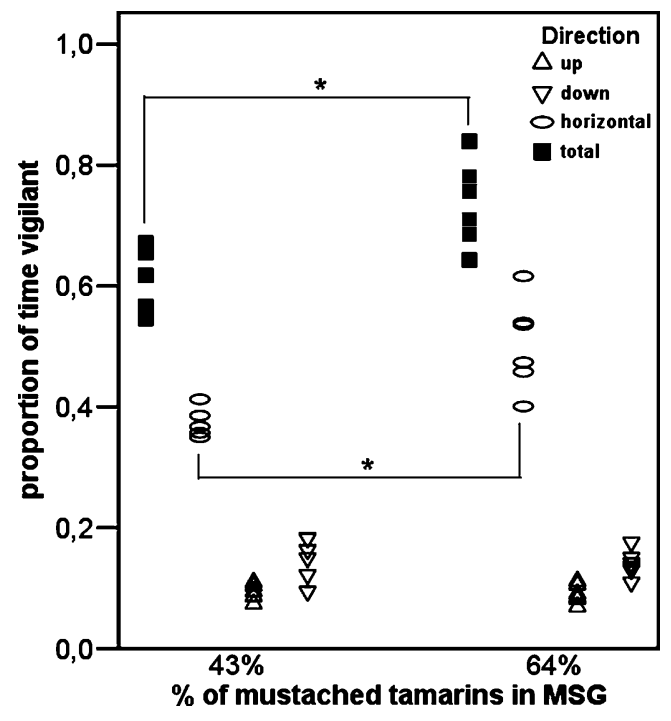

Fig. 4 Proportion of time spent vigilant for individuals from two MSG of the same total size but with different percentage of conspecifics. Data points represent individual mean values. ${ }^{*} p=0.05$ level of significance

could hardly have an ecological significance, it was about twofold at PI. It seems that tamarins in the population that has no contact with other primate species compensate for the absence of heterospecifics by increased scanning downwards.

However, comparisons of vigilance behavior in cases A and $\mathrm{C}$ gave results that were less straightforward. Individuals that were temporarily out of association (case A) increased their total vigilance as predicted by the group size effect, but that was due to horizontal, not downward, scanning. A similar behavioral response was observed when comparing individuals in the group with a higher percentage of conspecifics with those in the group with a smaller percentage of conspecifics (case C), although we predicted no difference in total vigilance levels in groups of the same size. We offer three explanations for why horizontal scanning increases in these two cases. First, non-antipredator functions such as food searching and especially social vigilance are probably much more included in horizontal than in upward or downward scanning because conspecifics are usually found at about the same height as the focal individual. Having other functions in addition to antipredator detection is probably also the reason why horizontal scanning takes up much more of animals' time than looking upwards or downwards (Table 2). In a group with more conspecifics (comparison C), there is probably an increased need for social vigilance. Our previous study suggests that, while the major function of vigilance is predator-related, the most probable reason for monitoring conspecific group members in mustached tamarins is maintaining group cohesion (Stojan-Dolar and
Heymann 2009). This certainly becomes more challenging with an increased number of conspecifics in the group. Yet, this interpretation does not explain why horizontal scanning increases when mustached tamarins are temporarily found out of association (comparison A). Other functions of social vigilance such as avoiding food stealing or aggression that are usually mentioned in studies on other species (e.g., Jones 1998; Steenbeek et al. 1999; Hirsch 2002) have not been found in the relatively non-aggressive society of these cooperatively breeding primates.

Second, due to the arboreal nature of neotropical felines callitrichids might increase horizontal or even upward scanning as a response to terrestrial predators (Barros et al. 2008). Neotropical felines and tayras can climb trees occasionally (Emmons 1987; Wang 2002), and the absence of the lower-living species certainly increases the probability that a predator climbing up a tree will remain unnoticed. This may be why mustached tamarins in both temporary and permanent SSG were found at greater heights than those in MSG (even though the forest at PI was actually lower than at EBQB), which gives an impression that this is a general reaction to the absence of heterospecifics that is not conditioned with the type of predators. The height of saddleback tamarins, on the other hand, is not affected by the presence or absence of congeners (Buchanan-Smith 1999), which may mean that they are more specialized to their specific niche and/or that there are antipredator benefits of living in lower forest strata.

And third, since mustached tamarins are found at higher levels in the forest and raptors are ambush predators that often perch within canopies (Rettig 1978; Robinson 1994), it might not be necessary to elevate the gaze for more than $45^{\circ}$ in order to detect them-especially since monkeys even further increase their height when in SSG. Horizontal scanning might therefore also have an important role in detection of aerial predators, and it has been understood as such also in some other vigilance studies (Peres 1993; Bshary and Noë 1997). Increased vigilance against raptors in a group of the same total size but with fewer heterospecifics (case $\mathrm{C}$ ) or in the absence of heterospecifics (case A) can imply that lower-ranging heterospecifics have a complementary role that cannot be compensated by adding additional conspecifics, not only in the detection of terrestrial but also aerial predators. This might occur because the lower-ranging saddlebacks see the upper levels of the forest and the sky from a different angle - a fact that could be important in a habitat with dense vegetation. But it can also emerge simply because the benefits of contributing vigilance in such a group are greater than in a group with more heterospecifics. In this case, contributing vigilance can be seen as a case of a component tragedy of the commons, where vigilance is a 
social good (Rankin et al. 2007). When the percentage of conspecifics is high, it is more likely that a predator would take a conspecific than when the percentage of conspecifics is low. Here, it is important to note that tamarins live in a highly cooperative society where reproductive success depends heavily on help from conspecifics (Caine 1993; Garber 1997) and where the degree of relatedness within the group is relatively high (Huck et al. 2005). Hence, if a predator kills a conspecific, this can have direct consequences for the fitness of other individuals - they lose a helper who is also quite likely to be a close relative. The associating species therefore both contribute vigilance to improve group safety, but the ratio between costs and benefits of contributing depends on the percentage of conspecifics in MSG. When the benefits/percentage of conspecifics are high, they tend to contribute more; when the benefits/percentage of conspecifics are low, they tend to free-ride more. However, vigilance can never drop under a certain level because individuals also increase their personal safety by being watchful.

In addition to that, individuals that are temporarily out of association (case A) are probably more vigilant already due to the group size effect. However, it remains unusual that upward scanning that certainly also serves detecting birds of prey did not increase.

A general observation based on our results is that the two populations did not respond in the same way to changes in group size and species composition. Tamarins from EBQB reacted by increasing total vigilance due to increased horizontal scanning, whereas the comparison with same-sized groups from PI revealed either no differences in vigilance or the expected changes in downward scanning (Fig. 1). Summarizing the abovedescribed mechanisms, we may explain the observed results as follows: In case $\mathrm{A}$, individuals that are temporarily out of association increased their vigilance due to the group size effect, the absence of the lowerranging species, and/or increased benefits of contributing vigilance. In case $\mathrm{B}$, individuals in the smaller groups from PI increased their vigilance against terrestrial predators due to the permanent absence of the lowerranging species. And in case $\mathrm{C}$, individuals in the group with a higher percentage of conspecifics increased their horizontal scanning due to an increased need to monitor conspecifics in order to maintain group cohesion and/or increased benefits of contributing vigilance.

It is difficult to speculate about the reasons for these mechanisms to act only under certain circumstances. However, there are two major differences between the populations that could give some clue as to why this occurs. First, the forest on PI is less dense and lower than at $\mathrm{EBQB}$, and as a consequence it is possible that there are different species of birds of prey present that might use different attack tactics. By recording alarm calls, we measured perceived predation risk, but we were not able to identify species that actually prey upon tamarins. Birds or conspecifics within the canopy are easier to detect in conditions of lower vegetation density, and therefore, benefits of increasing horizontal vigilance in order to monitor conspecifics or to detect aerial predators are not the same as at EBQB. Furthermore, there are no felines or tyras on the island, which means that horizontal scanning is unlikely to be intended to detect terrestrial predators. However, terrestrial threat is not absent as monkeys perceive dogs as potential predators. And second, tamarins at PI do not have any experience with other primate species, while animals at EBQB have had an opportunity to learn to adjust their vigilance according to the group species composition. Being only temporarily out of association or having a lower percentage of heterospecifics in MSG might elicit different reactions than living permanently in SSG and not having any experience with other primates.

Comparison with results of other studies on primate MSG that are analogous to our comparison A also implies that there is no uniform explanation for changes of vigilance patterns under different MSG/SSG conditions (Table 3). Individuals in different combinations of African cercopithecids have been observed to increase, decrease, or not to change their total vigilance at all when they are temporarily found in SSG, which appears to depend on which species they associate with (Cords 1990; Chapman and Chapman 1996; Bshary and Noë 1997; Treves 1999). With regard to callitrichids, a study on captive red-bellied (S. labiatus) and saddleback tamarins revealed that higherranging red-bellied tamarins increased "scanning" when they were housed without saddlebacks (Buchanan-Smith and Hardie 1997; Hardie and Buchanan-Smith 1997). Since the definition of "scanning" in that study included also looking sideways, these results might be consistent with our findings.

Mixed results are not uncommon in vigilance literature. The effects of sex, age, distance to cover, and also group size on vigilance vary greatly across different species and studies (reviewed in Caro 2005; Beauchamp 2008). Inconsistent results from studies on different species could occur due to differences in predation pressure between sites and species, differences in typical group sizes of different species, but also differences in methodology employed by different researchers. In order to facilitate comparison between species and populations, future studies should differentiate between all three possible directions of vigilance and take into account that vigilance can have a social as well as an antipredator component that might show different patterns (Klose et al. 2009). Different studies 
Table 3 An overview of primate studies comparing vigilance behavior in and out of association (analog to comparison A in this study)

\begin{tabular}{|c|c|c|c|}
\hline Study & Species & Forest stratum & $\begin{array}{l}\text { Changes of vigilance patterns when } \\
\text { temporarily in SSG }\end{array}$ \\
\hline \multirow[t]{2}{*}{ Cords $1990^{\mathrm{a}}$} & Blue monkeys (Cercopithecus mitis) & Higer & $\begin{array}{l}\text { When feeding on plants, frequency of } \\
\text { look-ups increases }\end{array}$ \\
\hline & Redtail monkeys (Cercopithecus ascanius) & Lower & $\begin{array}{l}\text { When feeding on plants, frequency } \\
\text { of look-ups increases }\end{array}$ \\
\hline \multirow[t]{2}{*}{ Bshary and Noë 1997} & Diana monkeys (Cercopithecus Diana) & Higher & No change in vigilance \\
\hline & Red colobus (Colobus badius) & Lower & $\begin{array}{l}\text { When foraging, frequency of looking } \\
\text { down and looking sideways increases }\end{array}$ \\
\hline \multirow[t]{2}{*}{ Treves $1999^{\mathrm{a}}$} & Red colobus (Colobus badius) & Higher & No change in vigilance \\
\hline & $\begin{array}{l}\text { Redtail monkeys } \\
\text { (Cercopithecus ascanius) }\end{array}$ & Lower & No change in vigilance \\
\hline \multirow[t]{5}{*}{ Chapman and Chapman $1996^{\mathrm{a}}$} & Black-and white colobus (Colobus guereza) & Highest & No change in vigilance \\
\hline & Red colobus (Colobus badius) & In between & $\begin{array}{l}\text { Depending on which species they associate } \\
\text { with, frequency of look-ups increases, } \\
\text { decreases, or does not change }\end{array}$ \\
\hline & Mangabeys (Cercocebus albigena) & In between & No change in vigilance \\
\hline & Blue monkeys (Cercopithecus mitis) & In between & $\begin{array}{l}\text { Depending on which species they associate } \\
\text { with, frequency of look-ups increases, } \\
\text { decreases, or does not change }\end{array}$ \\
\hline & Redtail monkeys (Cercopithecus ascanius) & Lowest & $\begin{array}{l}\text { Depending on which species they associate } \\
\text { with, frequency of look-ups increases, } \\
\text { decreases, or does not change }\end{array}$ \\
\hline \multirow[t]{3}{*}{ Stanford $1998^{\mathrm{a}}$} & Red colobus (Colobus badius) & Highest & $\begin{array}{l}\text { Frequency of look-ups increases in both } \\
\text { associations }\end{array}$ \\
\hline & Blue monkeys (Cercopithecus mitis) & In between & Not measured \\
\hline & Redtail monkeys (Cercopithecus ascanius) & Lowest & Not measured \\
\hline \multirow[t]{2}{*}{ Wolters and Zuberbühler 2003} & Diana monkeys (Cercopithecus Diana) & Higher & Percentage of time spent vigilant increases \\
\hline & $\begin{array}{l}\text { Campbell's monkeys } \\
\text { (Cercopithecus campbelli) }\end{array}$ & Lower & Percentage of time spent vigilant increases \\
\hline \multirow[t]{2}{*}{ Buchanan-Smith and Hardie 1997} & $\begin{array}{l}\text { Captive red-bellied tamarins } \\
\text { (Saguinus labiatus) }\end{array}$ & Higher & $\begin{array}{l}\text { Percentage of time spent scanning }{ }^{\mathrm{b}} \\
\text { increases }\end{array}$ \\
\hline & $\begin{array}{l}\text { Captive saddleback tamarins } \\
\text { (Saguinus fuscicollis) }\end{array}$ & Lower & $\begin{array}{l}\text { Percentage of time spent looking up and } \\
\text { scanning }{ }^{b} \text { increases }\end{array}$ \\
\hline \multirow[t]{2}{*}{ This study } & Mustached tamarins (Saguinus mystax) & Higher & $\begin{array}{l}\text { Percentage of time spent looking } \\
\text { sideways increases }\end{array}$ \\
\hline & Saddleback tamarins (Saguinus fuscicollis) & Lower & Not measured \\
\hline
\end{tabular}

${ }^{\text {a } A p p r o x i m a t e ~ f o r e s t ~ s t r a t a ~ b a s e d ~ o n ~ G e b o ~ a n d ~ C h a p m a n ~(1995) . ~}$

${ }^{\mathrm{b}}$ Scanning in this study is defined as "moving the head from side to side and/or up and down in a continuous flux of movement, excluding fixated stares or scanning the floor area." Look-ups are defined as "deliberate large single head movement upwards or a stare in an upward direction where the head is usually angled $45^{\circ}$ or more and not moving side to side"

also operate with different measures of vigilance (percentage of time vigilant, frequency/duration of vigilance bouts) that appear to give different results (e.g., Trouilloud et al. 2004; Beauchamp 2008).

To sum up, we found indications that associating tamarin species in MSG might complement each other in the direction of vigilance, but the division of labor alone does not satisfactorily explain all the findings. There appear to be other mechanisms at work that define how direction of vigilance changes with group size and species composition. However, this does not directly contradict the notion that heterospecifics have a complementary role in antipredator strategies of MSG. The two species notice different predators already because they live in different forest strata (Gautier-Hion et al. 1983; Peres 1993) and might additionally complement each other by seeing the same predators from different angles; therefore, additional adjustments in the direction of vigilance may not always be necessary. In this case, division of labor between species is still very important, it just does not occur due to differences in the direction of vigilance but rather due to vertical stratification per se. 
Interestingly, increasing the height in the forest appears to be a more uniform reaction to the absence of heterospecifics than changes in vigilance patterns. Data on more groups and populations and on responses of lower-ranging saddleback tamarins would be needed to gain clearer insight into mechanisms and ecological relevance of complementarity of antipredator behavior in species participating in MSG.

Acknowledgments We would like to thank the following people and organizations: Instituto Veterinario de Investigaciones Tropicales y de Altura (IVITA) for the permission to work on Padre Isla; our field assistants Camilo Flores Amasifuen, Ney Shahuano Tello, and Manuel Shahuano Tello for their invaluable help in the forest; Carlos Ique for helpful practical advice; and Markus Port and other members of the Department for Behavioural Ecology and Sociobiology of the German Primate Centre for many fruitful discussions. The manuscript benefited greatly from helpful advice of two anonymous reviewers. Financial support was partially provided by Deutscher Akademischer Austausch Dienst (DAAD). Field work was authorized by the Instituto Nacional de Recursos Naturales (authorization no. 018-2006INRENA-IFF-DCB) and complied with Peruvian laws.

Open Access This article is distributed under the terms of the Creative Commons Attribution Noncommercial License which permits any noncommercial use, distribution, and reproduction in any medium, provided the original author(s) and source are credited.

\section{References}

Barros M, Alencar C, Silva MAD, Tomaz C (2008) Changes in experimental conditions alter anti-predator vigilance and sequence predictability in captive marmosets. Behav Process 77:351-356

Beauchamp G (2008) What is the magnitude of the group-size effect on vigilance? Behav Ecol 19:1361-1368

Bshary R, Noë R (1997) Red colobus and Diana monkeys provide mutual protection against predators. Anim Behav 54:1461-1474

Buchanan-Smith HM (1999) Tamarin polyspecific associations: forest utilization and stability of mixed-species groups. Primates 40:233-247

Buchanan-Smith HM, Hardie SM (1997) Tamarin mixed-species groups: an evaluation of a combined captive and field approach. Folia Primatol 68:272-286

Caine NG (1993) Flexibility and co-operation as unifying themes in Saguinus social organization and behaviour: the role of predation pressures. In: Rylands $\mathrm{AB}$ (ed) Marmosets and tamarins: systamatics, behaviour, and ecology. Oxford University Press, Oxford, pp 200-219

Caro T (2005) Antipredator defenses in birds and mammals. University of Chicago Press, Chicago

Chapman CA, Chapman LJ (1996) Mixed-species primate groups in the Kibale forest: ecological constraints on association. Int $\mathbf{J}$ Primatol 17:31-50

Cords M (1990) Vigilance and mixed-species association of some East African forest monkeys. Behav Ecol Sociobiol 26:297-300

Ehrlich PR, Ehrlich AH (1973) Coevolution-heterotypic schooling in Caribbean reef fishes. Am Nat 107:157-160

Emmons LH (1987) Comparative feeding ecology of felids in a neotropical rainforest. Behav Ecol Sociobiol 20:271-283

Fitzgibbon CD (1990) Mixed-species grouping in Thomson and Grant gazelles - the antipredator benefits. Anim Behav 39:1116-1126
Galef BG, Mittermeier RA, Bailey RC (1976) Predation by tayra (Eira barbara). J Mammal 57:760-761

Garber PA (1997) One for all and breeding for one: cooperation and competition as a tamarin reproductive strategy. Evol Anthropol 5 (6): 187-199

Garber PA, Pruetz JD (1995) Positional behavior in moustached tamarin monkeys - effects of habitat on locomotor variability and locomotor stability. J Hum Evol 28:411-426

Garber PA, Pruetz JD, Isaacson J (1993) Patterns of range use, range defense, and intergroup spacing in moustached tamarin monkeys (Saguinus mystax). Primates 34:11-25

Gautier-Hion A, Quris R, Gautier JP (1983) Monospecific vs. polyspecific life - a comparative study of foraging and antipredatory tactics in a community of Cercopithecus monkeys. Behav Ecol Sociobiol 12:325-335

Gebo DL, Chapman CA (1995) Positional behavior in 5 sympatric Old-World monkeys. Am J Phys Anthropol 97:49-76

Hamilton WD (1971) Geometry for the selfish herd. J Theor Biol 31:295-311

Hardie SM, Buchanan-Smith HM (1997) Vigilance in single- and mixed-species groups of tamarins (Saguinus labiatus and Saguinus fuscicollis). Int J Primatol 18:217-234

Hardie SM, Buchanan-Smith HM (2000) Responses of captive singleand mixed-species groups of Saguinus to novel nonthreatening objects. Int J Primatol 21:629-648

Herzing D, Johnson C (1997) Interspecific interactions between Atlantic spotted dolphins (Stenella frontalis) and bottlenose dolphins (Tursiops truncatus) Bahamas, 1985-1995. Aqua Mamm 23(2):85-99

Heymann EW (1990a) Reactions of wild tamarins, Saguinus mystax and Saguinus fuscicollis to avian predators. Int J Primatol 11:327-337

Heymann EW (1990b) Social behaviour and infant carrying in a group of moustached tamarins, Saguinus mystax (Primates: Platyrrhini: Callitrichidae), on Padre Isla, Peruvian Amazonia. Primates 31:183-196

Heymann EW (1995) Sleeping habits of tamarins, Saguinus mystax and Saguinus fuscicollis (Mammalia; Primates; Callitrichidae), in north-eastern Peru. J Zool 237:211-226

Heymann EW (1996) Social behavior of wild moustached tamarins, Saguinus mystax, at the Estacion Biologica Quebrada Blanco, Peruvian Amazonia. Am J Primatol 38:101-113

Heymann EW, Buchanan-Smith HM (2000) The behavioural ecology of mixed-species troops of callitrichine primates. Biol Rev 75:169-190

Hill RA, Dunbar RIM (1998) An evaluation of the roles of predation rate and predation risk as selective pressures on primate grouping behaviour. Behaviour 135:411-430

Hirsch BT (2002) Social monitoring and vigilance behavior in brown capuchin monkeys (Cebus apella). Behav Ecol Sociobiol 52:458-464

Huck M, Löttker P, Bohle UR, Heymann EW (2005) Paternity and kinship patterns in polyandrous moustached tamarins (Saguinus mystax). Am J Phys Anthropol 127:449-464

Ique C (2000) Manejo semi-extensivo de Saguinus mystax en Padre Isla, río Amazonas. In: Howard F, García Podestá M (eds) La Primatología en el Perú 2 Master Graf Editores, Lima, pp 131-143

Jones ME (1998) The function of vigilance in sympatric marsupial carnivores: the eastern quoll and the Tasmanian devil. Anim Behav 56:1279-1284

Kirchhof J (2003) Raubfeindvermeidung bei Tamarinen im Amazonas-Regenwald von Peru: Alarmrufsysteme und Vigilanz in polyspezifischen Assoziationen. $\mathrm{PhD}$ thesis. Freie Universität Berlin, Berlin

Klose S, Welbergen J, Goldizen A, Kalko E (2009) Spatio-temporal vigilance architecture of an Australian flying-fox colony. Behav Ecol Sociobiol 63:371-380 
Löttker P, Huck M, Heymann EW (2004) Demographic parameters and events in wild moustached tamarins (Saguinus mystax). Am J Primatol 64:425-449

Martin P, Bateson P (1990) Measuring behaviour - an introductory guide. Cambridge University Press, Cambridge

McGraw WS, Bshary R (2002) Association of terrestrial mangabeys (Cercocebus atys) with arboreal monkeys: experimental evidence for the effects of reduced ground predator pressure on habitat use. Int J Primatol 23:311-325

Metcalfe NB (1984) The effects of mixed-species flocking on the vigilance of shorebirds: who do they trust? Anim Behav 32:986-993

Morse DH (1977) Feeding behavior and predator avoidance in heterospecific groups. Bioscience 27:332-339

Munn CA (1986) Birds that cry wolf. Nature 319:143-145

Noë R, Bshary R (1997) The formation of red colobus-diana monkey associations under predation pressure from chimpanzees. Proc R Soc B-Biol Sci 264:253-259

Oversluijs Vasquez MR, Heymann EW (2001) Crested eagle (Morphnus guianensis) predation on infant tamarins (Saguinus mystax and Saguinus fuscicollis, Callitrichinae). Folia Primatol 72:301-303

Peres CA (1993) Anti-predation benefits in a mixed-species group of Amazonian tamarins. Folia Primatol 61:61-76

Porter LM (2001) Benefits of polyspecific associations for the goeldi's monkey (Callimico goeldii). Am J Primatol 54:143-158

Pulliam HR (1973) On advantages of flocking. J Theor Biol 38:419-422

Rankin DJ, Bargum K, Kokko H (2007) The tragedy of the commons in evolutionary biology. Trends Ecol Evol 22:643-651

Rettig NL (1978) Breeding behavior of the harpy eagle (Harpia harpyja). Auk 95:629-643

Robinson SK (1994) Habitat selection and foraging ecology of raptors in Amazonian Peru. Biotropica 26:443-458

Semeniuk CAD, Dill LM (2006) Anti-predator benefits of mixedspecies groups of cowtail stingrays (Pastinachus sephen) and whiprays (Himantura uarnak) at rest. Ethology 112:33-43

Shahuano Tello N, Huck M, Heymann EW (2002) Boa constrictor attack and successful group defence in moustached tamarins, Saguinus mystax. Folia Primatol 73:146-148

Shelden KEW, Baldridge A, Withrow DE (1995) Observations of rissos dolphins (Grampus griseus) with gray whales (Eschrichtius robustus). Mar Mamm Sci 11:231-240

Smith AC, Kelez S, Buchanan-Smith HM (2004) Factors affecting vigilance within wild mixed-species troops of saddleback
(Saguinus fuscicollis) and moustached tamarins (S. mystax). Behav Ecol Sociobiol 56:18-25

Stanford C (1998) Chimpanzee and red colobus: the ecology of predator and prey. Harvard University Press, Cambridge

Steenbeek R, Piek R, van Buul M, van Hooff JARAM (1999) Vigilance in wild Thomas's langurs (Presbytis thomasi): the importance of infanticide risk. Behav Ecol Sociobiol 45:137150

Stensland E, Angerbjorn A, Berggren P (2003) Mixed species groups in mammals. Mamm Rev 33:205-223

Stojan-Dolar M, Heymann EW (2009) Vigilance in a cooperatively breeding primate. Int J Primatol (in press)

Struhsaker TT (1981) Polyspecific associations among tropical rainforest primates. Zeitschrift Für Tierpsychologie 57:268304

Terborgh J (1983) Five new world primates: a study in comparative ecology. Princeton University Press, Princeton

Terborgh J (1990) Mixed flocks and polyspecific associations: costs and benefits of mixed groups to birds and monkeys. Am J Primatol 21:87-100

Thompson DBA, Barnard CJ (1983) Anti-predator responses in mixed-species associations of lapwings, golden plovers and black-headed gulls. Anim Behav 31:585-593

Tornow MA, Ford SM, Garber PA, Sauerbrunn ED (2006) Dentition of moustached tamarins (Saguinus mystax mystax) from Padre Isla, Peru, part 1: quantitative variation. Am J Phys Anthropol 130:352-363

Treves A (1998) The influence of group size and neighbors on vigilance in two species of arboreal monkeys. Behaviour $135: 453-481$

Treves A (1999) Has predation shaped the social systems of arboreal primates? Int J Primatol 20:35-67

Trouilloud W, Delisle A, Kramer DL (2004) Head raising during foraging and pausing during intermittent locomotion as components of anitipredator vigilance in chipmunks. Anim Behav 67:789-797

Wang E (2002) Diets of ocelots (Leopardus pardalis), margays ( $L$. wiedii), and oncillas (L. tigrinus) in the Atlantic rainforest in southeast Brazil. Stud Neotrop Fauna E 37:207-212

Wolters S, Zuberbühler K (2003) Mixed-species associations of Diana and Campbell's monkeys: the costs and benefits of a forest phenomenon. Behaviour 140:371-385 